\title{
Influence of Must Supplementation on Growth of Pediococcus spp. after Alcoholic Fermentation
}

\author{
M.E. Wade ${ }^{1}$, J.P. Osborne ${ }^{2}$, C.G. Edwards*,1 \\ (1) School of Food Science, Washington State University, Pullman, WA, USA 99164-6376 \\ (2) Department of Food Science and Technology, Oregon State University, Corvallis, OR, USA 97331
}

Submitted for publication: September 2018

Accepted for publication: November 2018

Key words: Pediococcus, nutrients, yeast assimilable nitrogen, wine spoilage

\begin{abstract}
One factor potentially affecting growth of wine spoilage microbes (e.g., Pediococcus spp.) is the presence of nutrients not consumed during alcoholic fermentation by Saccharomyces cerevisiae. To assess the impact of must nutrient supplementation on Pediococcus spp., synthetic grape musts containing low (55.2 mg N/L), medium (250 mg N/L), or high (530 mg N/L) concentrations of yeast assimilable nitrogen (YAN) were fermented by $S$. cerevisiae. Upon cessation of fermentative activity $P$. damnosus $\mathbf{O W}-2, P$. inopinatus OW-8, $P$. parvulus WS-7C, WS-29A, OW-1, or P. pentosaceus ATCC 33316 were inoculated at $10^{4}$ to $10^{5} \mathrm{cfu} / \mathrm{mL}$. With the exceptions of $\mathrm{OW}-1$ and $\mathrm{OW}-2$, none of the other species or strains grew in the synthetic wines unless yeast extract or peptone was added, suggesting the absence of an essential nutrient. Experiments were replicated using Cabernet Sauvignon musts containing low (66.9 mg N/L), medium (219 mg N/L), and high (438 mg N/L) YAN. In general, wines containing the greatest residual amino acid concentrations (high YAN) supported better growth of the aforementioned Pediococcus spp. However, low YAN wines containing negligible residual nitrogen achieved similar populations after a short period of initial inhibition, suggesting that 'excessive' nitrogen supplementation to musts does not have a large impact on growth of pediococci post alcoholic fermentation.
\end{abstract}

\section{INTRODUCTION}

Generally considered a spoilage microorganism in winemaking (Lonvaud-Funel, 1999), Pediococcus spp. have been isolated throughout vinification, especially during wine aging (Wade et al., 2018). More recently, it has been argued that the frequencies of infections may be increasing (Wade et al., 2018), potentially due to changes to viticulture conditions which impact must composition. As an example, the higher $\mathrm{pH}$ of grape musts commonly associated with current viticulture practices (Mira de Orduña, 2010) favors growth of Pediococcus spp. as these bacteria dominate microflora in wines above $\mathrm{pH} 3.5$ (Wibowo et al., 1985; Davis et al., 1986). Furthermore, at $\mathrm{pH}>3.5$, the antimicrobial form of $\mathrm{SO}_{2}$ (i.e., molecular $\mathrm{SO}_{2}$ or $\mathrm{SO}_{2} \cdot \mathrm{H}_{2} \mathrm{O}$ ) is in less abundance, thereby increasing the risk of spoilage (Fugelsang \& Edwards, 2007).

Besides higher $\mathrm{pH}$, modern grape musts also tend to have high sugar concentrations $\left(>23^{\circ}\right.$ Brix $)$ which necessitate supplementation with nitrogen-containing nutrients to avoid problem alcoholic fermentations (Bisson \& Butzke, 2000). Common industry practice has been to add diammonium phosphate (DAP) or proprietary blends containing DAP, amino acids, and/or other nutrients to grape musts (Munoz \& Ingledew, 1990; Bell \& Henschke, 2005). However, excessive addition of these formulations prior to alcoholic fermentation may yield enough residual nutrients after fermentation (i.e., "carry-over") which support subsequent infections by spoilage microbes. Although Childs et al. (2015) reported that excessive nutrients added to synthetic grape juice media did not greatly impact growth of Brettanomyces bruxellensis in the resultant wines, little information is available regarding any impact of nutrient carry-over on bacteria such as pediococci. Furthermore, given the different nutritional requirements of B. bruxellensis and Pediococcus spp. or other lactic acid bacteria (Conterno et al., 2006; Terrade \& Mira de Orduña, 2009; Childs et al., 2015; Von Cosmos \& Edwards, 2016; Wade et al., 2018), it cannot be assumed that residual nutrients in wine will affect these microorganisms in a similar manner.

The objective of this study therefore was to evaluate the impact of adding yeast nutrients to grape musts on the subsequent growth of Pediococcus spp. inoculated after alcoholic fermentation.

\section{MATERIALS AND METHODS}

Microorganisms and starter culture preparation

Microorganisms were propagated as nutrient-rich starter

\footnotetext{
*Corresponding author: E-mail address: edwardsc@wsu.edu

Acknowledgments: The authors gratefully acknowledge the Washington State Grape and Wine Research Program, Northwest Center for Small Fruits Research, regional and national wineries, and the School of Food Science at Washington State University for financial and material support
} 
cultures prior to inoculation of grape musts or wines. Saccharomyces cerevisiae D254 was obtained as an active dry culture (Lallemand Inc., Montréal, Quebec, Canada) and maintained on yeast peptone dextrose (YPD) agar slants. Yeast starter cultures were prepared by aseptic transfer of single colonies into YPD broth $(500 \mathrm{~mL})$ with stirring $\left(25^{\circ} \mathrm{C}\right)$. Pediococcus parvulus WS-7C and WS29A (Edwards \& Jensen, 1992), P. parvulus OW-1, $P$. damnosus OW-2, and P. inopinatus OW-8 (Strickland et al., 2016), and P. pentosaceus ATCC 33316 (American Type Culture Collection, Manassas, VA, USA) were maintained on modified apple juice Rogosa medium (MR) agar slants as described by Fugelsang \& Edwards (2007) or frozen in MR broth containing $30 \% \mathrm{v} / \mathrm{v}$ glycerol at $-80^{\circ} \mathrm{C}$. Bacterial starter cultures were prepared by transferring single colonies from MR agar to $100 \mathrm{~mL}$ of MR broth and incubating for one week $\left(26^{\circ} \mathrm{C}\right)$. Weekly transfers of one $\mathrm{mL}$ of culture to fresh MR broth containing increasing amounts of ethanol $(0 \%, \mathrm{v} / \mathrm{v} ; 5 \%, \mathrm{v} / \mathrm{v} ; 10 \%, \mathrm{v} / \mathrm{v})$ were conducted over 21 days of incubation. Yeast and bacterial cells were harvested and suspended for must inoculation according to the protocol/ procedure of Osborne \& Edwards (2006).

\section{Synthetic grape juice media}

Synthetic grape juice media (SGJM) which simulate grape musts as described by Wang et al. (2003) were prepared to yield three different concentrations of yeast assimilable nitrogen (YAN) from different proportions of ammonia and amino acids (Table 1). The low (55.2 mg N/L) and high (250 $\mathrm{mg} \mathrm{N} / \mathrm{L}$ ) YAN media were prepared as described by Wang et al. (2003), the latter being identified as "medium YAN" in the present work. In addition, media with much higher amounts of YAN (530 mg N/L) and designated "high YAN" were prepared that contained Ala $(413 \mathrm{mg} / \mathrm{L})$, $\operatorname{Arg}(1.25 \mathrm{~g} / \mathrm{L})$, Asp (131 mg/L), Glu (522 mg/L), Gly (38 mg/L), His (283 mg/L), Ile (169 mg/L), Leu (205 mg/L), Lys (243 mg/L), Met (74 mg/L), Phe (169 mg/L), Pro (13.0 g/L), Ser (300 mg/L), Thr (261 mg/L), Trp (113 mg/L), Tyr $(131 \mathrm{mg} / \mathrm{L})$, and Val $(1.14 \mathrm{~g} / \mathrm{L})$. Media were further supplemented with adenine sulfate $(5 \mathrm{mg} / \mathrm{L})$, biotin $(10 \mu \mathrm{g} / \mathrm{L})$, cytosine $(5 \mathrm{mg} / \mathrm{L})$, thymidine $(5 \mathrm{mg} / \mathrm{L})$, Tween ${ }^{\mathrm{TM}} 80(0.05 \mathrm{~g} / \mathrm{L})$, uracil $(5 \mathrm{mg} / \mathrm{L})$, and xanthine $(5 \mathrm{mg} / \mathrm{L})$ obtained from Fisher Scientific (Pittsburgh, PA, USA), cysteine (5 mg/L) and calcium pantothenate $(250 \mu \mathrm{g} / \mathrm{L})$ obtained from SigmaAldrich (St. Louis, MO, USA), and guanine $\bullet \mathrm{HCl}(5 \mathrm{mg} / \mathrm{L})$ from Spectrum Chemical Mfg. Corp. (New Brunswick, NJ, USA). SGJM was sterile-filtered through $0.22 \mu \mathrm{m}$ Steritop $^{\mathrm{TM}}$ Sterile Vacuum Bottle-Top Filters (EMD Millipore, Billerica, MA, USA) into $3 \mathrm{~L} \mathrm{Celstir}^{\circledR}$ vessels, in triplicate, prior to inoculation of $S$. cerevisiae at $10^{4} \mathrm{cfu} / \mathrm{mL}$. After 14 days of fermentation at $21^{\circ} \mathrm{C}$, wines were again sterile-filtered into sterilized milk dilution bottles $(100 \mathrm{~mL})$. A powdered cellulose suspension (Sigmacell Type 20, Sigma Aldrich, St. Louis, MO, USA) was added to each bottle according to Childs et al. (2015). Pediococcus spp. were inoculated at initial populations of $10^{4}$ to $10^{5} \mathrm{cfu} / \mathrm{mL}$ (six replicates per treatment), the exception being $P$. pentosaceus which was inoculated at $10^{3} \mathrm{cfu} / \mathrm{mL}$. Wines were then incubated at $25^{\circ} \mathrm{C}$ for up to 75 days.

\section{Spiking synthetic wines}

After incubation with Pediococcus spp. for 75 days, the low and high YAN wines were subjected to additional nutrient supplementation and re-inoculation. Here, replicate wines were pooled, centrifuged $(1000 \times \mathrm{g}$ for $10 \mathrm{~min})$, and sterilefiltered $(0.22 \mu \mathrm{m})$ with $10 \mathrm{~mL}$ dispensed into sterile $15 \mathrm{~mm}$ X $125 \mathrm{~mm}$ capped test tubes. All tubes received a sterilized cellulose suspension $(1 \mathrm{~g} / \mathrm{L})$ and one of the following $0.22 \mu \mathrm{m}$ filter-sterilized solutions: peptone $(5 \mathrm{~g} / \mathrm{L})$, yeast extract $(5 \mathrm{~g} / \mathrm{L})$, liver extract $(1 \mathrm{~g} / \mathrm{L})$, Tween $^{\mathrm{TM}} 80(0.1 \mathrm{~g} / \mathrm{L})$, cysteine $(0.2 \mathrm{~g} / \mathrm{L})$, asparagine $(0.8 \mathrm{~g} / \mathrm{L}), \mathrm{MnSO}_{4} \bullet 4 \mathrm{H}_{2} \mathrm{O}(0.8 \mathrm{~g} / \mathrm{L})$, biotin $(100 \mu \mathrm{g} / \mathrm{L})$, or calcium pantothenate $(1000 \mu \mathrm{g} / \mathrm{L})$. Pediococcus spp. were re-inoculated, in triplicate, at initial populations of $10^{5}$ to $10^{6} \mathrm{cfu} / \mathrm{mL}$, except $P$. pentosaceus which was inoculated at $10^{3} \mathrm{cfu} / \mathrm{mL}$. Tubes were incubated at $26^{\circ} \mathrm{C}$ for 24 days.

\section{Cabernet Sauvignon musts}

Cabernet Sauvignon grape juice concentrate (California Concentrate Company, Acampo, CA, USA) was diluted according to the manufacturer's instructions and sugar adjusted by adding equal proportions of glucose and fructose. In addition, the must was supplemented with biotin $(10 \mu \mathrm{g} / \mathrm{L})$, calcium pantothenate $(250 \mu \mathrm{g} / \mathrm{L})$, and other vitamins and trace minerals as described by Wang et al. (2003). Titratable acidity was adjusted to $6.8 \mathrm{~g} / \mathrm{L}$ by the addition of tartaric and malic acids in a 5:3 (w/w) ratio while free $\mathrm{SO}_{2}$ was removed to $<3 \mathrm{mg} / \mathrm{L}$ using $\mathrm{H}_{2} \mathrm{O}_{2}$ as confirmed by the aeration oxidation method (Buechsenstein \& Ough, 1978). After cold-settling overnight $\left(4^{\circ} \mathrm{C}\right)$, the YAN content was adjusted with various amounts of DAP and/or amino acids (Wang et al., 2003) as presented in Table 2.

For fermentation, musts were sterile-filtered through $0.45 \mu \mathrm{m}$ Vitipore ${ }^{\circledR}$ II Plus Cartridge Filters (EMD Millipore, Billerica, MA, USA) into 3 L Celstir $^{\circledR}$ fermentation vessels (Wheaton Science Products, Millville, NJ, USA), in triplicate. S. cerevisiae was inoculated at populations of $10^{6} \mathrm{cfu} / \mathrm{mL}$ with fermentations conducted at $21^{\circ} \mathrm{C}$ for 14 days. Alcoholic fermentation was deemed complete when the concentrations of reducing sugars reached $<2 \mathrm{~g} / \mathrm{L}$ as determined by Bayer Clinitest ${ }^{\circledR}$ tablets (Fugelsang \& Edwards, 2007). Each of the resulting wines were rackedoff and subdivided into previously sterilized milk dilution bottles $(100 \mathrm{~mL})$. Pediococcus spp. were inoculated at $10^{5}$ to $10^{6} \mathrm{cfu} / \mathrm{mL}$ (six replicates per wine), the exception being $P$. pentosaceus which was inoculated at $10^{4}$ to $10^{5} \mathrm{cfu} / \mathrm{mL}$ prior to incubation at $25^{\circ} \mathrm{C}$.

\section{Analytical methods}

Culturability was determined by spiral plating using an Autoplate 4000 (Spiral Biotech, Bethesda, MD, USA) on YPD for Saccharomyces and MR with cycloheximide $(0.1 \mathrm{~g} / \mathrm{L})$ for Pediococcus. Plates were incubated at $26^{\circ} \mathrm{C}$ for three days (Saccharomyces) or 14 days (Pediococcus spp.) prior to enumeration. In addition, growth of Pediococcus spp. in test tubes was monitored by measuring absorbance at $550 \mathrm{~nm}$ using a FLUOstar ${ }^{\circledR}$ OPTIMA Microplate Reader (BMG Labtech, Cary, NC, USA) over a 24 day period. Here, population estimates were made by comparing optical density values to corresponding culturability ( $\mathrm{cfu} / \mathrm{mL}$ ) on 
TABLE 1

Composition of synthetic grape juice media pre- and post-alcoholic fermentation.

\begin{tabular}{|c|c|c|c|}
\hline Pre-alcoholic fermentation & Low YAN & Medium YAN & High YAN \\
\hline Alpha-amino nitrogen $[\mathrm{mg} / \mathrm{L}]$ & $29.6 \pm 12$ & $238 \pm 5.8$ & $524 \pm 3.9$ \\
\hline Ammonia [mg/L] & $25.6 \pm 0.92$ & $12.2 \pm 2.9$ & $5.87 \pm 0.64$ \\
\hline${ }^{\circ}$ Brix & $21.7 \pm 0.50$ & $22.5 \pm 0.08$ & $23.2 \pm 0.14$ \\
\hline $\mathrm{pH}$ & $3.67 \pm 0.01$ & $3.62 \pm 0.00$ & $3.48 \pm 0.00$ \\
\hline Total YAN [mg N/L] & $55.2 \pm 2.0$ & $250 \pm 3.3$ & $530 \pm 3.3$ \\
\hline \multicolumn{4}{|l|}{ Post-alcoholic fermentation } \\
\hline Alpha-amino nitrogen $[\mathrm{mg} / \mathrm{L}]$ & nd & $35.0 \pm 4.6$ & $260 \pm 8.1$ \\
\hline Ammonia $[\mathrm{mg} / \mathrm{L}]$ & nd & nd & nd \\
\hline Ethanol $[\% \mathrm{ABV}]$ & $9.08 \pm 0.11$ & $13.0 \pm 0.06$ & $13.0 \pm 0.09$ \\
\hline Fructose $[\mathrm{g} / \mathrm{L}]$ & $41.2 \pm 0.91$ & nd & $0.167 \pm 0.14$ \\
\hline Glucose $[\mathrm{g} / \mathrm{L}]$ & $17.9 \pm 2.5$ & nd & nd \\
\hline $\mathrm{pH}$ & $3.67 \pm 0.01$ & $3.81 \pm 0.00$ & $3.69 \pm 0.00$ \\
\hline Titratable acidity $[\mathrm{g} / \mathrm{L}$ tartaric acid $]$ & $7.21 \pm 0.16$ & $6.58 \pm 0.09$ & $8.09 \pm 0.05$ \\
\hline Volatile acidity [g/L acetic acid] & $0.44 \pm 0.00$ & $0.93 \pm 0.01$ & $0.88 \pm 0.00$ \\
\hline
\end{tabular}

Values represent means of triplicate fermentations \pm standard error nd: Not detected

TABLE 2

Composition of Cabernet Sauvignon grape musts pre- and post-alcoholic fermentation.

\begin{tabular}{lccc}
\hline Pre-alcoholic fermentation & Low YAN & Medium YAN & High YAN \\
\cline { 2 - 4 } Alpha-amino nitrogen [mg/L] & $40.8 \pm 0.92$ & $196 \pm 15$ & $428 \pm 17$ \\
Ammonia [mg/L] & $26.0 \pm 1.5$ & $23.5 \pm 0.63$ & $9.80 \pm 1.4$ \\
${ }^{\circ}$ Brix & $19.3 \pm 0.31$ & $20.1 \pm 0.03$ & $20.7 \pm 0.03$ \\
$\mathrm{pH}$ & $3.90 \pm 0.00$ & $3.84 \pm 0.00$ & $3.83 \pm 0.00$ \\
Total YAN [mg N/L] & $66.9 \pm 2.4$ & $219 \pm 15$ & $438 \pm 16$ \\
\hline Post-alcoholic fermentation & & & \\
Alpha-amino nitrogen [mg/L] & $2.5 \pm 1.9$ & $14.8 \pm 2.0$ & $165 \pm 10$ \\
Ammonia [mg/L] & nd & $1.26 \pm 0.48$ & $1.58 \pm 0.27$ \\
Ethanol [\% ABV] & $10.4 \pm 0.10$ & $11.3 \pm 0.03$ & $11.4 \pm 0.01$ \\
Fructose [g/L] & $3.93 \pm 1.2$ & $\mathrm{nd}$ & $\mathrm{nd}$ \\
Glucose [g/L] & $\mathrm{nd}$ & $\mathrm{nd}$ & $3.89 \pm 0.00$ \\
pH & $3.72 \pm 0.00$ & $3.78 \pm 0.00$ & $6.38 \pm 0.15$ \\
Titratable acidity [g/L tartaric acid] & $6.64 \pm 0.20$ & $6.29 \pm 0.04$ & $0.27 \pm 0.02$ \\
Volatile acidity [g/L acetic acid] & $0.36 \pm 0.00$ & $0.32 \pm 0.01$ &
\end{tabular}

Values represent means of triplicate fermentations \pm standard error nd: Not detected

standard growth curves prepared for each microorganism in MR broth.

Concentrations of ethanol were determined using an Agilent 1100 HPLC system equipped with refractive index detector (Agilent Technologies, Santa Clara, CA, USA) according to the method of Hall \& Reuter (2007). Residual glucose and fructose were determined enzymatically using commercially available kits (Megazyme, K-FRUGL, Bray, Ireland). Titratable and volatile acidities were determined by standard methods (Edwards \& Watson, 2013) while alpha- 
amino nitrogen concentration was measured by the NOPA assay (Dukes \& Butzke, 1998). Ammonia concentrations were determined using an ion selective electrode (McWilliam \& Ough, 1974). Statistical analyses were performed with XLSTAT (Addinsoft, New York, NY, USA) with ANOVA and Fisher's LSD for mean separations.

\section{RESULTS AND DISCUSSION}

\section{Fermentation of synthetic grape juice media}

Determining the nutritional requirements of wine microorganisms often necessitates the utilization of synthetic media to accurately control concentrations of the nutrients in question (Liu et al., 1995; Osborne \& Edwards, 2006; 2007; Terrade \& Mira de Orduña, 2009; Childs et al., 2015). SGJM was therefore chosen to evaluate the impact of forms of nitrogen remaining after alcoholic fermentation on the growth of pediococci. This medium had been previously used to evaluate post-alcoholic growth of a spoilage yeast, B. bruxellensis (Childs et al., 2015) and, with addition of purines and pyrimidines, O. oeni (Osborne \& Edwards, 2006; 2007). Given similar nutrient requirements as $O$. oeni, enough nutrients should have been present to support Pediococcus spp. (Nakagawa \& Kitahara, 1959).

Low, medium and high YAN synthetic grape musts yielded wines which contained different amounts of alphaamino nitrogen and other chemical constituents (Table 1). Medium or high YAN grape musts produced dry wines $(<2 \mathrm{~g} / \mathrm{L}$ glucose and fructose) containing 13\% (v/v) ethanol while those with low amounts of nitrogen did not complete fermentation. Low YAN musts yielded wines that only contained $9.08 \%(\mathrm{v} / \mathrm{v})$ ethanol with approximately $59 \mathrm{~g} / \mathrm{L}$ residual sugar $(17.9 \mathrm{~g} / \mathrm{L}$ glucose and $41.2 \mathrm{~g} / \mathrm{L}$ fructose). The fact that these fermentations did not complete was not unexpected as the amount of alpha amino nitrogen in the musts was well below the minimum nitrogen requirements reported for successful fermentation (Agenbach, 1977; Spayd et al., 1995). While residual alpha-amino nitrogen was not detected in low YAN wines, wines produced from medium and high YAN SGJM contained 35.0 and $260 \mathrm{mg}$ $\mathrm{N} / \mathrm{L}$ residual nitrogen, respectively (Table 1). Ammonia was not detected in any of the wines following alcoholic fermentation.

With the exception of $P$. parvulus (OW-1) and $P$ damnosus (OW-2), bacterial culturability generally quickly declined after inoculation in the synthetic wines. Even with low amounts of ethanol present, populations of all strains quickly declined in low YAN wines, with many being reduced to undetectable levels within just a few days (Fig. 1). Strains WS-7C, WS-29A and OW-8 eventually recovered and became culturable but remained $\leq 10^{4} \mathrm{cfu} / \mathrm{mL}$ up to 50 days post inoculation in these wines. In contrast, populations of $P$. parvulus $\mathrm{OW}-1$ and $P$. damnosus $\mathrm{OW}-2$ decreased over a short time period (approximately 15 days) following inoculation before recovering to reach $10^{5} \mathrm{cfu} / \mathrm{mL}$ in low YAN wines. Besides P. parvulus OW-1, none of the strains were recovered from wines produced from SGJM containing medium or high YAN (Fig. 1).

The limited growth of pediococci in wines produced from SGJM may be due to (a) synthesis of an inhibitory substance(s) by $S$. cerevisiae during the alcoholic fermentation or (b) absence or insufficient quantity of an unidentified required nutrient. For example, better growth in wines produced from SGJM with low YAN compared to medium and high amounts may have been due to the lower concentration of ethanol $(9 \%$ vs. $13 \% \mathrm{v} / \mathrm{v})$. While ethanol tolerances for some pediococci have been reported to be upwards of $14 \%$ to $16 \%$ (Maret \& Sozzi, 1977; Silver \& Leighton, 1981; Edwards \& Jensen, 1992), Davis et al. (1988) noted that growth of pediococci decreased as ethanol increased from $12.5 \%$ to $15 \% \mathrm{v} / \mathrm{v}$. In fact, pediococci exhibited growth in low YAN wines despite limited concentrations of nitrogen-containing substances compared to medium and high YAN wines that contained measurable amounts of alpha amino nitrogen (35.0 and $260.1 \mathrm{mg} \mathrm{N} / \mathrm{L}$, respectively).

Aside from ethanol, $S$. cerevisiae is known to produce a range anti-bacterial compounds (Edwards \& Beelman, 1987; Capucho \& San Ramao, 1994; Carrete et al., 2002; Comitini et al., 2005; Osborne \& Edwards, 2006; 2007). While Osborne \& Edwards (2006) reported increased inhibition of $O$. oeni when grown in wines fermented from musts containing high amounts of nitrogen, Wibowo et al. (1988) observed growth of P. parvulus in Shiraz wines following alcoholic fermentation and MLF by Leuconostoc oenos (O. oeni). In fact, Vilanova et al. (2007) noted a correlation between nitrogen concentration and production of decanoic acid by wine yeast, a compound associated with the inhibition of O. oeni (Edwards \& Beelman, 1987).

Rather than explore the possible existence of yeastproduced inhibitory compounds, poor growth in the synthetic wines was investigated through addition of selected nutrients. Additions of asparagine, biotin, calcium pantothenate, cysteine, liver extract, manganese sulfate, or Tween $80^{\mathrm{TM}}$ to wines made from SGJM had little to no effect on growth for most strains (data not shown) despite being important growth factors for lactic acid bacteria (Nakagawa \& Kitahara, 1959; De Man et al., 1960; Garvie \& Gregory, 1961; Holzapfel et al., 2009). However, addition of peptone or yeast extract improved growth of strain WS-7C (Fig. 2), thereby suggesting a lack of nutritional component(s) as opposed to the presence of inhibitory substance(s). In fact, peptone encouraged growth of five of the six strains studied (excluding $P$. pentosaceus) while yeast extract promoted strong growth of all six strains (data not shown). These results were in agreement with Nel et al. (2001) which demonstrated better growth of $P$. damnosus in MRS media if supplemented with peptone or meat extract, with yeast extract or tryptone also improving growth to a lesser extent.

The specific cause of growth stimulation due to peptone and/or yeast extract is not well understood. Early research by Snell et al. $(1937 \mathrm{a} ; 1937 \mathrm{~b})$ reported that the stimulatory impact of peptone on lactic acid bacteria may be due to a basic amino acid or a compound with similar properties. Being prepared from cytoplasmic constituents of S. cerevisiae (Ángeles Pozo-Bayón et al., 2009), yeast extract is rich in peptides (Martínez-Rodriguez et al., 2001) and contributes free amino acids, lipids, vitamins/ minerals, and several trace elements (Grant \& Pramer, 1962; Ángeles Pozo-Bayón et al., 2009). While it is difficult to identify specific factor(s) responsible for the growth enhancement of pediococci, commercial musts or wines are 


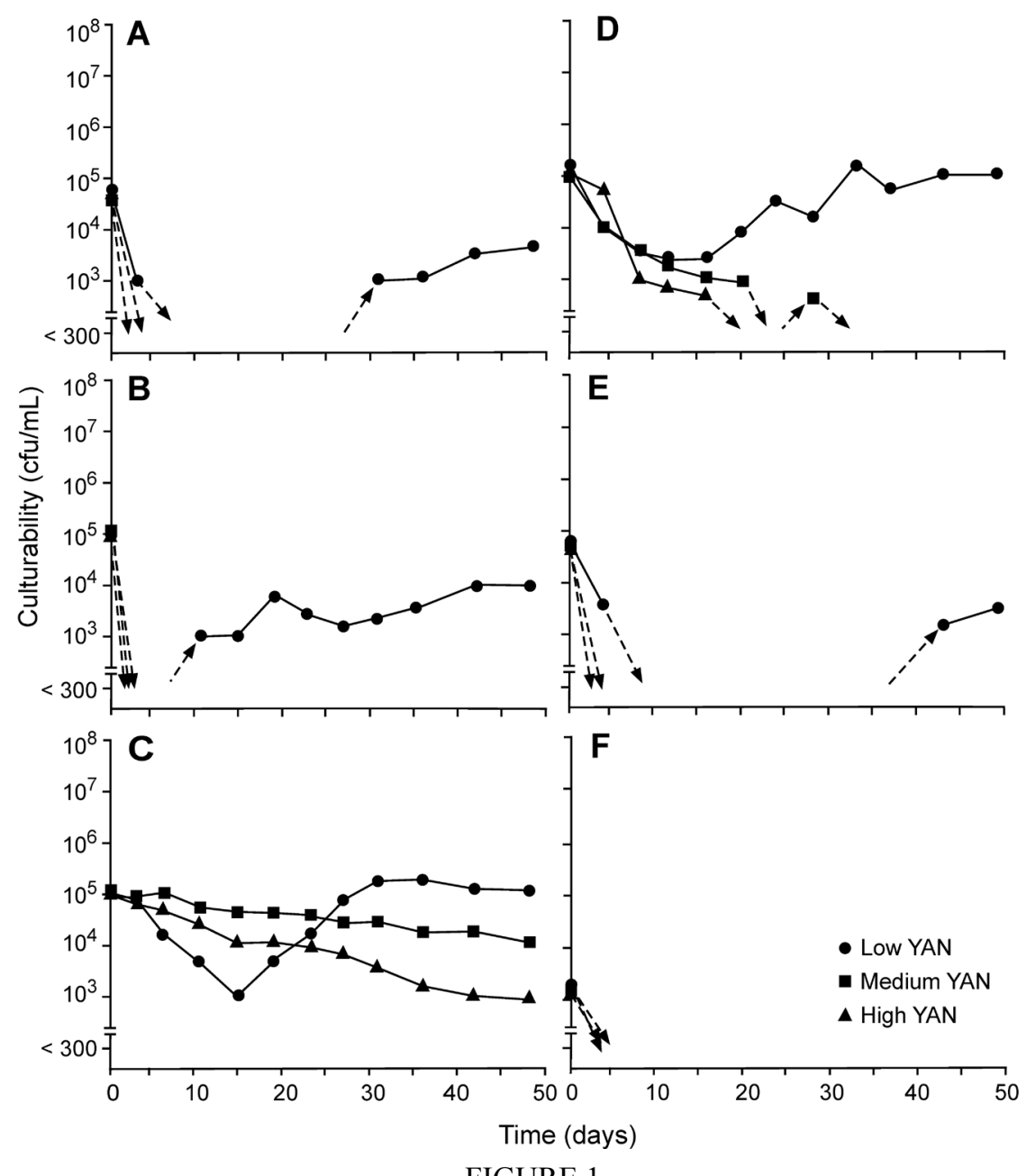

FIGURE 1

Culturability of P. parvulus strains WS-7C (A), WS-29A (B), and OW-1 (C), P. damnosus OW-2 (D), P. inopinatus OW-8 (E), or P. pentosaceus ATCC 33316 (F) in synthetic wines prepared from SGJM initially containing $55.2 \mathrm{mg} \mathrm{N} / \mathrm{L}$ (low), $250 \mathrm{mg}$ $\mathrm{N} / \mathrm{L}$ (medium), or $530 \mathrm{mg} \mathrm{N} / \mathrm{L}$ (high) YAN before alcoholic fermentation.

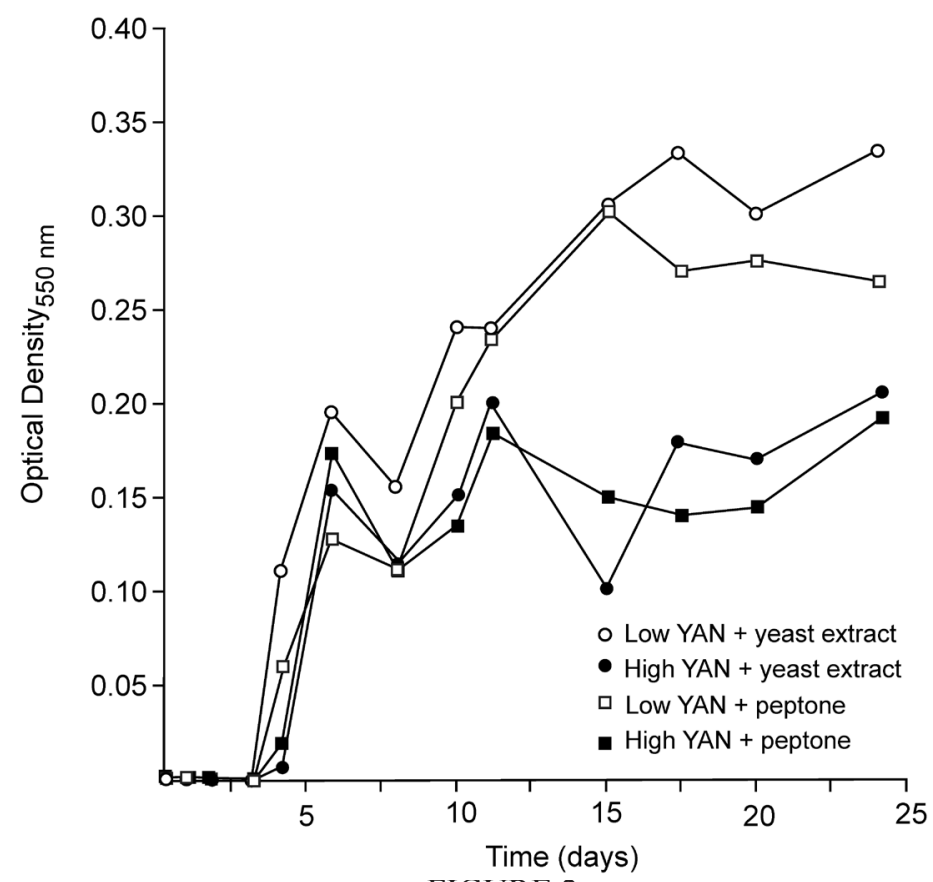

FIGURE 2

Re-inoculation and growth of $P$. parvulus WS-7C in synthetic wines additionally supplemented with yeast extract or peptone. 


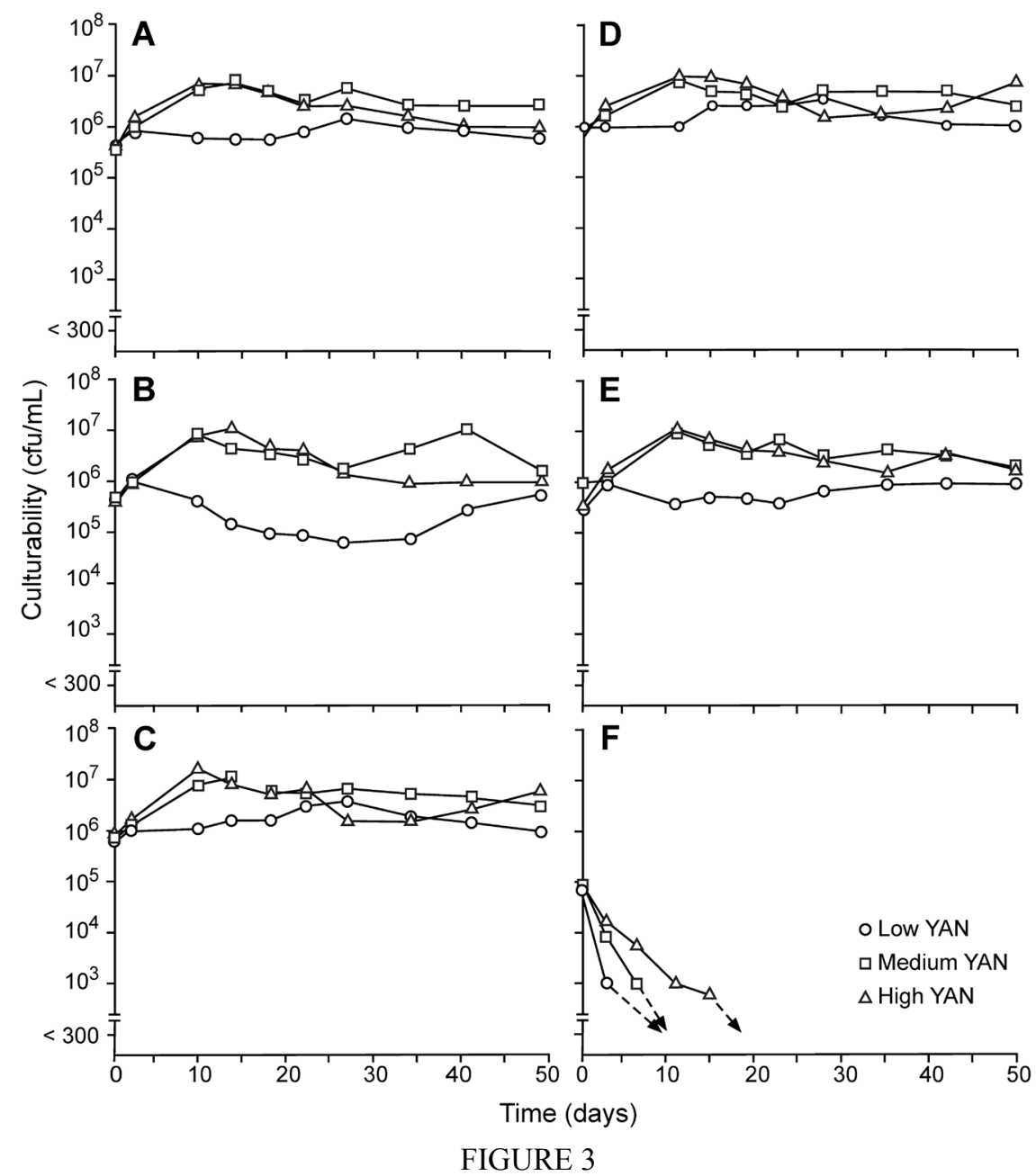

Culturability of P. parvulus strains WS-7C (A), WS-29A (B), and OW-1 (C), P. damnosus OW-2 (D), P. inopinatus OW-8 (E), or $P$. pentosaceus ATCC 33316 (F) in Cabernet Sauvignon wines prepared from grape musts initially containing $67 \mathrm{mg}$ N/L (low), $219 \mathrm{mg} \mathrm{N} / \mathrm{L}$ (medium), or $438 \mathrm{mg} \mathrm{N} / \mathrm{L}$ (high) YAN before alcoholic fermentation.

often supplemented with inactive dry yeast preparations as a means to stimulate alcoholic or malolactic fermentations (Ángeles Pozo-Bayón et al., 2009). Furthermore, wines can be stored with lees during aging (Ángeles Pozo-Bayón et al., 2009) where enzymatic degradation of yeast cells liberates nitrogen-containing compounds (peptides and free amino acids), polysaccharides, and fatty acids (Charpentier \& Feuillat, 1993).

\section{Fermentation of Cabernet Sauvignon musts}

Given poor growth in wines made from SGJM, pediococci were inoculated into Cabernet Sauvignon wines where YAN values were altered prior to alcoholic fermentation. Alcoholic fermentation conducted by $S$. cerevisiae was complete $(<2 \mathrm{~g} / \mathrm{L}$ residual sugar) within ten days for all treatments with the exception of the low YAN must which became stuck with an average of $3.9 \mathrm{~g} / \mathrm{L}$ residual fructose (Table 2). Wines produced from musts containing low or medium amounts of YAN also contained lower concentrations of residual amino nitrogen than those made from high YAN musts, in agreement with Sturgeon et al. (2013) and Childs et al. (2015). Ammonium was depleted from all wines to concentrations $<2 \mathrm{mg} \mathrm{N} / \mathrm{L}$.
Unlike the observations using SGJM, most of the Pediococcus species grew well in the Cabernet Sauvignon wines. However, growth of pediococci in wines produced from low YAN musts differed from wines produced from medium or high YAN (Fig. 3). Specifically, populations of $\geq 10^{7} \mathrm{cfu} / \mathrm{mL}$ were achieved by $P$. parvulus (WS-7C, WS29A and OW-1), P. damnosus (OW-2), or P. inopinatus $(\mathrm{OW}-8)$ in wines produced from medium or high YAN grape musts, the exception being P. pentosaceus (ATCC 33316) which died-off soon after inoculation. Although less growth was observed in wines fermented from low YAN musts, bacterial populations of $10^{5}$ to $10^{6} \mathrm{cfu} / \mathrm{mL}$ were reached despite containing only $2.5 \mathrm{mg} \mathrm{N} / \mathrm{L}$. In fact, wines prepared from medium YAN musts contained nearly 11 times less residual amino nitrogen than high YAN (Table 2) yet were able to support similar populations of pediococci. These observations suggest that low concentrations of residual amino nitrogen were enough to support the growth of different species of Pediococcus, similar to previous findings regarding Brettanomyces bruxellensis (Childs et al., 2015).

Although stuck/sluggish fermentations may be more susceptible to unwanted microbial growth (Bisson \& Butzke, 2000), wines produced from the medium and high 
YAN grape musts that completed fermentation similarly supported bacterial growth as those produced from low YAN grape musts that did not complete fermentation. In this case, the presence of higher residual sugar and lower ethanol in the low YAN wines did not improve pediococci growth compared to the medium and high YAN wines, although all wines contained $<12 \% \mathrm{v} / \mathrm{v}$ alcohol.

The frequency at which winemakers encounter nitrogen deficient grape musts has resulted in supplementation guidelines to avoid the addition of excessive amounts of nutrients (Ingledew \& Kunkee, 1985; Bisson \& Butzke, 2000 ) in order to avoid risk of subsequent microbial spoilage (Beltran et al., 2004). However, growth of pediococci in the present study were not greatly impacted by increased levels of residual nitrogen in the wines. While negligible levels of residual amino nitrogen present in some of the Cabernet Sauvignon wines led to increased lag times for bacterial growth, these wines ultimately reached similar populations as wines containing high concentrations of residual nitrogen. As such, the results of this study suggest that the amount of ethanol had more of an inhibitory impact on Pediococcus spp. growth than the presence of amino nitrogen. Additional research involving $O$. oeni, Lactobacillus spp., and/or non-Saccharomyces yeasts is warranted to better evaluate impacts of excessive must supplementation on the potential for subsequent spoilage by microorganisms other than Pediococcus spp.

\section{CONCLUSIONS}

Increased YAN concentration in grape musts resulted in increased residual amino nitrogen in subsequent wines which theoretically could be utilized by Pediococcus spp. after completion of fermentation. However, amino nitrogen had a limited effect on Pediococcus growth in comparison to ethanol concentration, the latter of which impacted growth more than nutrient availability. The poor growth of Pediococcus spp. in synthetic wines was improved with addition of peptone or yeast extract, suggesting the absence or insufficient concentration of an unidentified essential growth factor(s).

\section{LITERATURE CITED}

Agenbach, W., 1977. A study of must nitrogen content in relation to incomplete fermentations, yeast production and fermentation activity. In: Proceedings of the South African Society of Enology and Viticulture, Cape Town. Stellenbosch, South Africa. South African Society of Enology and Viticulture. pp. 66-88.

Ángeles Pozo-Bayón, M., Andújar-Ortiz, I. \& Moreno-Arribas, M.V., 2009. Scientific evidences beyond the application of inactive dry yeast preparations in winemaking. Food Res. Int. 42, 754-761.

Bell, S.J. \& Henschke, P.A., 2005. Implications of nitrogen nutrition for grapes, fermentation and wine. Aust. J. Grape. Wine Res. 11, 242-295.

Beltran, G., Novo, M., Rozès, N., Mas, A. \& Guillamón, J.M., 2004. Nitrogen catabolite repression in Saccharomyces cerevisiae during wine fermentations. FEMS Yeast Res. 4, 625-632.

Bisson, L.F. \& Butzke, C.E., 2000. Diagnosis and rectification of stuck and sluggish fermentations. Am. J. Enol. Vitic. 51, 168-177.

Buechsenstein, J.W. \& Ough, C.S., 1978. SO determination by aerationoxidation: a comparison with Ripper. Am. J. Enol. Vitic. 29, 161-164.
Capucho, I. \& San Ramao, M.V., 1994. Effect of ethanol and fatty acids on malolactic activity of Leuconostoc oenos. Appl. Microbiol. Biotechnol. 42, 391-395.

Carrete, R., Vidal, M., Bordons, A. \& Constanti, M., 2002. Inhibitory effect of sulfur dioxide and other stress compounds in wine on the ATPase activity of Oenococcus oeni. FEMS Microbiol. Lett. 211, 155-159.

Charpentier, C. \& Feuillat, M., 1993. Yeast autolysis. In: G.H. Fleet (ed.), Wine Microbiology and Biotechnology. Harwood Academic Publishers, Chur, Switzerland. pp. 225-242.

Childs, B.C., Bohlscheid, J.C. \& Edwards, C.G., 2015. Impact of available nitrogen and sugar concentration in musts on alcoholic fermentation and subsequent wine spoilage by Brettanomyces bruxellensis. Food Microbiol. 46, 604-609.

Comitini, F., Ferretti, R., Clementi, F., Mannazzu, I. \& Ciani, M., 2005. Interactions between Saccharomyces cerevisiae and malolactic bacteria: preliminary characterization of a yeast proteinaceous compound(s) active against Oenococcus oeni. J. Appl. Microbiol. 99, 105-111.

Conterno, L., Joseph, C.M.L., Arvik, T.J., Henick-Kling, T. \& Bisson, L.F. 2006. Genetic and physiological characterization of Brettanomyces bruxellensis strains isolated from wines. Am. J. Enol. Vitic. 57, 139-147.

Davis, C.R., Wibowo, D., Fleet, G.H. \& Lee, T.H., 1988. Properties of wine lactic acid bacteria: their potential enological significance. Am. J. Enol. Vitic. 39, 137-142.

Davis, C.R., Wibowo, D.J., Lee, T.H. \& Fleet, G.H., 1986. Growth and metabolism of lactic acid bacteria during fermentation and conservation of some Australian wines. Food Aust. 38(1), 35-40.

De Man, J.C., Rogosa, M. \& Sharpe, M.E., 1960. A medium for the cultivation of lactobacilli. J. Appl. Bacteriol. 23, 130-135.

Dukes, B.C. \& Butzke, C.E., 1998. Rapid determination of primary amino acids in grape juice using an $o$-phthaldialdehyde/N-acetyl-L-cysteine spectrophotometric assay. Am. J. Enol. Vitic. 49, 125-134.

Edwards, C.G. \& Beelman, R.B., 1987. Inhibition of the malolactic bacterium, Leuconostoc oenos (PSU-1), by decanoic acid and subsequent removal of the inhibition by yeast ghosts. Am. J. Enol. Vitic. 38, 239-242.

Edwards, C.G. \& Jensen, K.A., 1992. Occurrence and characterization of lactic acid bacteria from Washington State wines: Pediococcus spp. Am. J. Enol. Vitic. 43, 233-238.

Edwards, C.G. \& Watson, B.A., 2013. Basic Microbiological and Chemical Analyses for Wine. Washington State University, Cooperative Extension EM047, Pullman, WA, USA.

Fugelsang, K.C. \& Edwards, C.G., 2007. Wine Microbiology: Practical Applications and Procedures. Springer Science and Business Media, New York, NY.

Garvie, E.I. \& Gregory, M.E., 1961. Folinic acid requirement of strains of the genus Pediococcus. Nature 190, 563-564.

Grant, C.L. \& Pramer, D., 1962. Minor element composition of yeast extract. J. Bacteriol. 84, 869-870.

Hall, G. \& Reuter, W.M., 2007. HPLC analysis for the monitoring of fermentation broth during ethanol production as a biofuel. PerkinElmer, Inc., Waltham, MA.

Holzapfel, W.H., Franz, C.M.A.P., Ludwig, W. \& Dicks, L.M.T., 2009. Genus III. Pediococcus Claussen 1903, 68. In: P.D. Vos, G.M. Garrity, D. Jones, N.R. Krieg, W. Ludwig, F.A. Rainey, K-H. Schleifer, \& W.B. Whitman, (eds.), Bergey's Manual of Systematic Bacteriology. Springer Science and Business Media, New York, NY, pp. 513-532.

Ingledew, W.M. \& Kunkee, R.E., 1985. Factors influencing sluggish fermentations of grape juice. Am. J. Enol. Vitic. 36, 65-76. 
Liu, S-Q., Davis, C.R. \& Brooks, J.D., 1995. Growth and metabolism of selected lactic acid bacteria in synthetic wine. Am. J. Enol. Vitic. 46, 166174

Lonvaud-Funel, A., 1999. Lactic acid bacteria in the quality improvement and depreciation of wine. Antonie van Leeuwenhoek 76, 317-331.

Maret, R. \& Sozzi, T. 1977. Flore malolactique de moûts et de vins du Canton du Valais (Suisse). I. Lactobacilles et pédiocoques. Ann. Technol. Agric. 27, 255-273.

Martínez-Rodriguez, A.J., Carrascosa, A.V. \& Polo, M.C., 2001. Release of nitrogen compounds to the extracellular medium by three strains of Saccharomyces cerevisiae during induced autolysis in a model wine system. Int. J. Food Microbiol. 68, 155-160.

McWilliam, D.J. \& Ough, C.S., 1974. Measurement of ammonia in musts and wines using a selective electrode. Am. J. Enol. Vitic. 25, 67-72.

Mira de Orduña, R., 2010. Climate change associated effects on grape and wine quality and production. Food. Res. Int. 43, 1844-1855.

Munoz, E. \& Ingledew, W.M., 1990. Yeast hulls in wine fermentations - a review. J. Wine. Res. 1, 197-209.

Nakagawa, A. \& Kitahara, K., 1959. Taxonomic studies on the genus Pediococcus. J. Gen. Appl. Microbiol. 5, 95-126.

Nel, H.A., Bauer, R., Vandamme, E.J. \& Dicks, L.M.T., 2001. Growth optimization of Pediococcus damnosus NCFB 1832 and the influence of $\mathrm{pH}$ and nutrients on the production of pediocin PD-1. J. Appl. Microbiol. 91, 1131-1138.

Osborne, J.P. \& Edwards, C.G., 2006. Inhibition of malolactic fermentation by Saccharomyces during alcoholic fermentation under low- and highnitrogen conditions: a study in synthetic media. Aust. J. Grape Wine Res. 12, 69-78.

Osborne, J.P. \& Edwards, C.G., 2007. Inhibition of malolactic fermentation by a peptide produced by Saccharomyces cerevisiae during alcoholic fermentation. Int. J. Food Microbiol. 118, 27-34.

Silver, J. \& Leighton, T., 1981. Control of malolactic fermentation in wine. 2. Isolation and characterization of a new malolactic organism. Am. J. Enol. Vitic. 32, 64-72.

Snell, E.E., Tatum, E.L. \& Peterson, W.H., 1937a. Growth factors for bacteria: III. Some nutritive requirements of Lactobacillus delbrückii. J. Bacteriol. 33, 207-225.
Snell, E.E., Strong, F.M. \& Peterson, W.H., 1937b. Growth factors for bacteria: Fractionation and properties of an accessory factor for lactic acid bacteria. Biochem. 31, 1789-1799.

Spayd, S.E., Nagel, C.W. \& Edwards, C.G., 1995. Yeast growth in Riesling juice as affected by vineyard nitrogen fertilization. Am. J. Enol. Vitic. 46 , $49-55$.

Strickland, M.T., Schopp, L.M., Edwards, C.G. \& Osborne, J.P., 2016. Impact of Pediococcus spp. on Pinot noir wine quality and growth of Brettanomyces. Am. J. Enol. Vitic. 67, 188-198.

Sturgeon, J.Q., Bohlscheid, J.C. \& Edwards, C.G., 2013. The effect of nitrogen source on yeast metabolism and $\mathrm{H}_{2} \mathrm{~S}$ formation. J. Wine Res. 24, 182-194.

Terrade, N. \& Mira de Orduña, R., 2009. Determination of the essential nutrient requirements of wine-related bacteria from the genera Oenococcus and Lactobacillus. Int. J. Food Microbiol. 133, 8-13.

Vilanova, M., Ugliano, M., Varela, C., Siebert, T., Pretorius, I.S. \& Henschke, P.A., 2007. Assimilable nitrogen utilisation and production of volatile and non-volatile compounds in chemically defined medium by Saccharomyces cerevisiae wine yeasts. Appl. Microbiol. Biotechnol. 77, 145-157.

Von Cosmos, N.H. \& Edwards, C.G., 2016. Use of nutritional requirements for Brettanomyces bruxellensis to limit infections in wine. Ferment. 2, 17.

Wade, M.E., Osborne, J.P., Strickland, M.T. \& Edwards C.G., 2018. Role of Pediococcus spp. in winemaking. Aust. J. Grape Wine Res. doi: 10.1111/ ajgw. 12366

Wang, X.D., Bohlscheid, J.C. \& Edwards, C.G., 2003. Fermentative activity and production of volatile compounds by Saccharomyces grown in synthetic grape juice media deficient in assimilable nitrogen and/or pantothenic acid. J. Appl. Microbiol. 94, 349-359.

Wibowo, D., Eschenbruch, R., Davis, C.R., Fleet, G.H. \& Lee, T.H., 1985. Occurrence and growth of lactic acid bacteria in wine: a review. Am. J. Enol. Vitic. 36, 302-313

Wibowo, D., Fleet, G.H., Lee, T.H. \& Eschenbruch, R.E., 1988. Factors affecting the induction of malolactic fermentation in red wines with Leuconostoc oenos. J. Appl. Microbiol. 64, 421-428. 